\title{
Handwriting at Grade 3: More Than a Matter of 'Neatness'
}

\author{
HETTY ROESSINGH \\ University of Calgary \\ DAVID NORDSTOKKE \\ University of Calgary
}

\begin{abstract}
This article reports on the role of the quality and fluency of handwriting and spelling on the writing outcomes for 222 Grade 3 students who attend a large, public school in a major urban center in Canada. Findings indicate that control over the exigencies of handwriting, and fluency account for a large proportion in the variability of quality writing outcomes. Spelling is important, but only indirectly, in predicting the quality writing outcomes. Samples of student work are provided to illustrate the quality standards for handwriting. We advocate for sustained attention to handwriting instruction, effortful practice and increased opportunities to write in a variety of genres for meaningful and authentic purposes.
\end{abstract}

\section{Introduction}

Achievement outcomes data for written literacy development in Grade 3 indicates cause for concern in Canada and internationally (Applebee \& Langer, 2006, 2009; Cutler $\&$ Graham, 2008). High levels of literacy - both in reading and writing, are increasingly required to engage with curriculum and contemporary pedagogical approaches that are predicated on strong foundational skills in legacy formats. Ultimately, high levels of literacy are required to engage with the complex demands of a globally interconnected community and workplace in both the digital and analogue worlds.

Various scholars suggest the root causes of the decline in written early literacy may be attributed to factors such as quality of printing or handwriting, terms we use interchangeably (Christensen, 2009; Graham, 2009), automaticity and fluency in handwriting (Berninger, 1999; McCutchen, 1996; Medwell \& Wray, 2014); and spelling (Berninger \& Fayol, 2008; Joshi, Treiman, Carreker, \& Moats, 2008). Our inquiry focuses on the transcription skills of handwriting and spelling and the question, 'how do they predict writing outcomes on 222 Grade 3 students' writing samples?' Illustrative samples are provided that can guide practitioners in understanding the role of handwriting and evaluating samples of student handwriting following a simple trait based rubric and fluency guidelines we provide.

Children leave indelible footprints in their journey to literacy learning in their written efforts. Studying samples of their written work generated in authentic classroom contexts illuminates their strengths and needs. Left unattended, inadequate control over handwriting and spelling may have detrimental consequences in the longitudinal academic literacy outcomes, as well as in digital literacy formats such as keyboarding (Christensen, 2005; Connelly \& Hurst, 2001; Peverly, 2006). 
The broad questions that guide our inquiry are as follows:

1) What is the influence of the quality of printing on the fluency - as measured by total number of words (TNW) of the writing sample? Printing was evaluated as (1) belabored, (2) legible, (3) controlled and (4) fluent following a trait-based rubric.

2) What is the influence of fluency of printing on the holistic rating of the writing sample? The samples were evaluated as (1) limited, (2) adequate, (3) proficient and (4) excellent) following a trait-based rubric.

3) What is the role of accurate spelling in the holistic rating of the writing sample?

Our major goal is pragmatic and aims for ecological validity in data collection and analysis. That is, we seek to work in the context of the classroom, gathering our writing samples on an authentic-like writing task following a process approach. Rubrics and illustrative samples for evaluating printing developed for the purposes of this research, and our reported findings are accessible to a practitioner readership, and intended to support their work in the classroom. Because Grade 3 is such a critical stage in children's literacy development, provincial jurisdictions across Canada typically choose this point for assessment of young learners' writing. Our findings provide useful information for assessment practices as well.

This article makes a unique contribution to practitioners' ability to glean holistic insights into young students' early written literacy development, and in turn, to use this information for planning instructional support, programming and assessment approaches for early written literacy development that can improve writing outcomes. In addition, we hope our work will influence policy decisions related to curriculum mandates at the jurisdictional level by underscoring that printing is more than a matter of neatness. Control over the transcription skills developed early in the educational trajectory have a lasting, distal impact on other literacy formats that are only beginning to come to light by way of evolving research, especially in the neurosciences. We aim to contribute to this body of research through knowledge mobilization/translation from clinical research to classroom based research that will have practical utility.

\section{Literature Review}

We recruit the theoretical underpinnings for our inquiry from the research domain of written literacy development, adopting the 'simple view of writing' advanced by Berninger (1999). In this section we describe Berninger's model and we review the relevant literature on early written literacy learning. We focus on the transcription skills of printing and spelling - the constrained skills that need to be under control to unleash the higher order skills and processes involved in text generation.

\section{The 'Simple View of Writing'}

For the purposes of our inquiry, we adopt Berninger's (1999) model of written literacy development, often referred to as the 'simple view of writing'. It is comprised of two separate components, namely transcription and text generation. The transcription skills involve printing and spelling, and are considered the lower level developmental skills. Text generation involves the more complex and higher order skills of vocabulary retrieval, for example, and places greater cognitive demand on planning, organizing, and revising text. 
Composing text, then, is a complex process that involves mobilizing a host of neuro-motor, psycholinguistic and higher order skills and resources, all within working memory. Our work focuses on the role of transcription skills of handwriting and spelling. Of all of the skills involved in composing text, handwriting places the greatest constraints on young writers (Graham, 2009; McCutchen, 1996).

To a proficient writer who has automatized handwriting and spelling, these transcription skills may seem mechanical and even taken for granted. But for a young writer, developing control over these skills is labor-intensive and effortful (Berninger, 1999). Mastery of these skills is foundational to furthering written literacy learning, in particular, the threshold required to unlock the higher order executive functions associated with planning, revising and editing writing, and retrieving low frequency and academic vocabulary associated with more cognitively demanding topics in Grade 4. Grade 3 is a pivotal point in children's literacy development with regard to gaining control over these transcription skills.

There has been a resurgence of interest within the scholarly community and among jurisdictional level decision makers in early written literacy, specifically, the lower level developmental skills of printing and spelling (Medwell, Strand, \& Wray, 2007; Medwell $\&$ Wray, 2008, 2014). This is visible, for example, in the re-introduction of handwriting instruction in several States and provinces in Canada, as well as increased recognition in the scholarly research on handwriting across disciplinary boundaries that includes occupational therapy (Roberts, Derkach-Ferguson, Siever, \& Rose, 2014; Stevenson \& Just, 2014); developmental neuropsychology (Peverly, 2006); and cognitive psychology (Connelly \& Hurst, 2001).

\section{Learning to Print}

Teaching and learning to print have long been marginalized on the curriculum. Neat printing for its own sake, and for its potential to influence subjective evaluation of student work even into post-secondary settings (Peverly, 2006) - a phenomenon described as presentation effect; and the introduction of computers and keyboarding skills for a generation of digital natives (Prensky, 2005) may all be contributing factors in the demise of handwriting instruction.

On January 23, 2012, some 150 scholars, practitioners, and policy makers convened in Washington, DC for Handwriting in the $21^{\text {st }}$ century: An educational summit (American Association for School Administrators, 2012; Saperstein Associates, 2012). This convention represents a turning point in the re-introduction of printing (manuscript) as well as handwriting into the curriculum across the United States as an offshoot of new insights evolving from research in the domains of developmental, cognitive, and neurosciences that illuminate the interconnectedness and the complexity of learning to print. The role of explicit instruction and 'readiness' is highlighted. Keyboarding is recognized along with handwriting as a key component of literacy learning in the $21^{\text {st }}$ century. Canadian jurisdictions have been somewhat slower in allocating instructional time to printing on the curriculum.

Dinehart (2014) provides a comprehensive and accessible review of the literature on early written literacy development. She underscores the importance of fine motor (fm) manipulation skills that facilitate hand-body-mind connections, especially as these relate to both literacy and numeracy learning. Sensory motor engagements such as playing with 
blocks and loose parts develops embodied cognition that consolidates concepts of shape, size and space, pattern and sequence, for example, that underlie print (reading) recognition, hence the writing-reading relationship. Kim, Al Otaiba, and Wanzek (2015) address these same underpinnings to early literacy development in their longitudinal work to the end of Grade 3. Further, children who have developed fm literacy related skills such as handling pencils, crayons, erasers, glue sticks and scissors have an early 'readiness' advantage when it comes time to engage in more formal handwriting instruction, usually in the second half of Grade 1 (Roberts et al., 2014).

Research findings as to the style of handwriting (manuscript versus cursive) that can support developing the speed requirements for school assignments and when (and if) cursive should be used are mixed (Bourne, 2007; Morin, Lavoie, \& Montesinos, 2012). There is consensus that speed, whether generated by manuscript, cursive or a hybrid style - described as mixed mostly manuscript (Graham, Berninger, \& Weintraub, 1998; Korbey, 2013) is key to fluency and automaticity that increases year by year into the middle school years, though in an uneven, non-linear fashion.

There is general consensus in the research that legible printing is dependent on producing script that is uniform and consistent in shape, size, space, slant (Alston, 1983; 1985; Anderson, 1969). Evaluation of legibility is often determined holistically by way of comparisons to writing samples that have been rated along the criteria noted above (Rosenblum, Weiss, \& Parush, 2003). Various researchers report that by the end of Grade 2 (and even earlier), 90\%+ of students are able to produce legible script (Graham, Berninger, \& Weintraub, 2001; Roberts et al., 2014; Roessingh, 2013) with only a few letters posing difficulty. Once young learners have internalized stable models of legible script from direct instruction, practice and explicit feedback on features such as shape, size, and slant they are themselves proficient at assessing their own productive efforts as early as Grade 3 (Boekaerts, Nieuwenhuizen, \& Seegers, 1992).

Writing fluency is a multi-faceted construct that involves speed, accuracy, and endurance. In the reported research findings it is usually measured by way of copying and timed tasks, for example, by asking young learners to print the letters of the alphabet as rapidly as possible for one minute, or by writing the sentence 'the quick brown fox jumped over the lazy dog' (it contains all of the letters of the alphabet). As a timed copying task these words may be presented in unpredictable order (Graham, Berninger, \& Weintraub, 1998). In another variation of timed printing, students were required to write their name as often as possible in 60 seconds; in yet another, students were required to write 'cat and dog' as often as possible within 2 minutes. Given the variability in task and time noted here, it becomes difficult to translate tests and findings designed for clinical purposes into usable guidelines for classroom practitioners (Rosenblum, Weiss, \& Parush, 2003). Moreover, generating text for authentic purposes in the context of the classroom is a far more complex task than timed letter copying or dictation. This is a key concern behind our work at hand.

Fluency as measured by total number of words (TNW) generated in an open ended writing task has also been taken as a proxy for speed in various studies and is further reported by Nelson and Van Meter (2007) to be a robust measure of developmental growth in writing in their longitudinal study covering Grades 1 to 7. Roessingh and Elgie (2015) found that TNW as a measure of fluency (and indirectly, of speed) correlated with writing quality in a study of Grade 2 writing. Finally, fluency, as operationalized as effective 
joining and copying of letters (Medwell \& Wray, 2014) is reported to contribute to automaticity (speed + accuracy).

Young learners' major task is to gain sufficient control over the neuro-motor demands of printing to make working memory space available for the higher order cognitive, linguistic and metacognitive processes involved in generating increasingly more sophisticated text, in expository mode (Christensen, 2009; Jones \& Christensen, 1999). While it will take yet some time before young learners demonstrate automaticity in printing or connected script, they must develop enough speed to produce the length and complexity of text for the demands of the writing assigned for increasingly academic purposes (Berninger, 1999; Jones \& Christensen, 1999).

To sum up, the quality and the quantity of handwriting (as a measure of fluency) together are key contributors to writing outcomes. These features relate to our first two inquiry questions.

\section{Learning to Spell}

Decades of research endeavor and the understandings gleaned from reported findings on how children learn and develop spelling acumen offers lessons for the classroom (Berninger et al., 2002; Ehri, 1987; Gentry, 1982; 2002; Graham, 2009; Moats, n.d.; Treiman \& Bourassa, 2000). The scholarly community has mapped out the progression of developmental steps to look for teaching ideas and graded spelling lists, among other useful resources that are research informed. There is strong consensus among these researchers that spelling instruction needs to be explicit, developmentally appropriate, progressive and programmatic. Despite reports in the media (Vangelova, 2015), on the impossible complexity of English orthography, accurate spelling by the end of Grade 3 is within the abilities of the vast majority of young students, particularly when they have been engaged in direct instruction (Gentry, 2002, 2010).

Learning to spell is a multi-faceted, developmental process that involves understanding of phonology (the sound system); orthography (the writing system) and morphology (the meaning system). It further includes pattern recognition and memory for 'word demons' all of which can be facilitated through explicit instruction and support in developing mnemonic devices, or strategies for remembering spellings that do not follow the usual phonics rules. Beyond Grade 3, there is a shift to understanding the meanings and spellings of Greek and Latin root words to apply to morphological problem solving. These words have high, general academic utility and transfer across curricular boundaries (Coxhead, 2000; Nagy, Berninger, Abbott, Vaughan, \& Vermeulen, 2001). Secondly, there is a rapid acceleration in discipline specific vocabulary. These two domains of academic vocabulary are challenging for young students, and a refocus on spelling instruction in the upper elementary grades is warranted. Reed (2012) writes a very accessible, practitioner oriented synthesis of the research that is worth further exploration.

Young learners are by and large only mobilizing words they have in their oral repertoire in narrative contexts. As they shift to expository modes of writing, young students are increasingly experimenting with more academic-like word choices, and for those who take these risks, various strategic approaches to spelling words just beyond their control - especially applying phonics knowledge, is evident (Roessingh \& Elgie, 2015; Roessingh, Douglas, \& Wojtalewicz, 2016). 
Spelling knowledge contributes to better writing outcomes in early literacy development by the end of Grade 2 (Berninger \& Fayol, 2008; Gentry, 2002; Joshi, Treiman, Carreker \& Moats, 2008; Roessingh \& Elgie, 2015). We investigate this question in the context of the Grade 3 writing samples in our present inquiry.

Figure 1 summarizes the progression in spelling proficiency in $\mathrm{K}-3$, adapted from Gentry (1982) for the purposes of our work.

Summary chart

\begin{tabular}{|c|l|l|}
\hline Stage: & Features: & $\begin{array}{l}\text { Approx. } \\
\text { age/Grade }\end{array}$ \\
\hline 1. Semiphonetic & $\begin{array}{l}\text { Begins to reflect understanding that letters } \\
\text { have sounds. Left to right. Alphabet } \\
\text { knowledge and letter formation. }\end{array}$ & $\begin{array}{l}\text { Short stage! } \\
\text { Age 5 }\end{array}$ \\
\hline $\begin{array}{l}\text { 2. Phonetic/letter } \\
\text { naming stage } \\
75-85 \% \text { correct }\end{array}$ & $\begin{array}{l}\text { Wide variety of writing forms (signs, lists, } \\
\text { notes, labels, captions, cards). Systematic } \\
\text { inventions, perceptually correct. Letters } \\
\text { assigned on the basis of sound. (eng, kat, } \\
\text { babe, ate for 80). }\end{array}$ & Grade 1 \\
\hline $\begin{array}{l}\text { Transitional } \\
\text { 35-95\% correct }\end{array}$ & $\begin{array}{l}\text { Moves from relying on phonology to visual } \\
\text { and morphological representations. Can } \\
\text { benefit from formal spelling instruction. } \\
\text { Relies on various means to spell: patterns, } \\
\text { phonics knowledge, memory. Look for } \\
\text { systematic errors that 'make sense' } \\
\text { (crevate/create; geraff/giraffe) }\end{array}$ & Grade 2 \\
\hline $\begin{array}{l}\text { Correct } \\
95 \% \text { correct }\end{array}$ & $\begin{array}{l}\text { Masters a certain corpus of word that has } \\
\text { been designated as 'grade level' (Gentry, } \\
\text { nd). Teach word awareness, and interest in } \\
\text { word origins; extend knowledge of word } \\
\text { structure (prefixes, suffixes, compound } \\
\text { words, homonyms). Ramp up the writing } \\
\text { expectations. }\end{array}$ & Grade 3 \\
\hline
\end{tabular}

Figure 1. Summary of the progression of spelling knowledge and skills

We turn next to the design of our study that seeks to address our framing questions related to the role of printing and spelling in student writing outcomes.

\section{Study Design}

In this section we describe the research site and the participants to give the reader context information for this work. We elaborate on the procedures, writing task - the prompt, the protocol for its administration and the rubrics designed to score and analyze the writing samples.

\section{Context of the Study}

The study was conducted in a single, publically funded $(K-12)$ school district within a large, urban center. This is a school of choice, and most children are bused to their school location. There are 8 campuses across the city that attract diverse learner demographics, however, the students are overall typical learners and none are coded for special needs or funding. This school district has a distinct instructional focus on teaching foundational skills associated with early literacy learning. 
The K - Grade 2 teachers use The Writing Road to Reading (Spalding, 2012), a systematic and integrated approach to the teaching of handwriting, spelling, and reading. There is a strong emphasis on explicit instruction in phonemic awareness, phonics, and sight word vocabulary. The program is consistently implemented by all teachers especially in the $\mathrm{K}$ - 2 grades.

Outcomes on provincially mandated tests of reading and writing at the Grade 3 level reflect provincial patterns of achievement in early literacy learning. All 13 classes of Grade 3 teachers and their students $(\mathrm{N}=222)$ volunteered to participate in this writing study, now in its seventh year. Young students are generally aged $8-9$ at the end of Grade 3 .

We have had a long partnership with this school district allowing us to conduct community-engaged research that prizes the reciprocal nature of research, staff development and school improvement planning based on the findings.

\section{Procedures}

Following an approved research ethics protocol, we collected writing samples from 222 Grade 3 students at the end of the school year. To glean insights into student's independent level of writing abilities, we collected first draft writing. We refer to our prompt as The Empty Space (see Appendix A, Writing prompt). Following a process approach to our data collection, pre-writing activity allowed for some teacher talk and 'think-pair-share' to focus the students' thoughts and to ensure they understood the writing task. Drawing, coloring and other pre-writing activity was also encouraged before the students were set to the task of writing with no further interaction with the teacher or their classmates. The students' regular classroom teachers administered the writing task within classroom time. Up to 60 minutes was allocated for the entire process.

Each writing sample was given a unique identification number, since this is part of a longitudinal writing study. The names of the students were removed before the samples were transferred to us for our research work.

\section{Scoring and Data Analysis}

To begin, the writing samples were digitized and marked for quality standard by way of a trait-based rubric adopted for the purposes of this research, and assigned a holistic score. The writing samples were rated by two independent researchers who were trained in the use of the rubric. Ratings assigned were 1: Limited; 2: Adequate; 3: Proficient; and 4: Excellent. An overall, first-pass reliability of $90 \%$ was achieved for the quality writing standards. For the $10 \%$ of cases with discrepancies in the scoring outcomes the PI (HR) revisited the papers and the differences between the two raters were reconciled to form a combined final rating (Johnson, Penny, Fisher, \& Kuhs, 2003).

Spelling errors were recorded and then corrected, counting each unique spelling error for each sample. As well, we recorded common patterns of spelling errors. Misspelled words are not recognized by the vocabulary profiling software program, and left uncorrected would artificially enhance the score for access to rare and low frequency vocabulary, the focus of a separate paper evolving from these data.

The digitized samples were then submitted to an online vocabulary profiling tool (www.lextutor.ca/vp/kids). Words from within the prompt, and 'kid' words that had the potential to inflate the vocabulary profile - largely content words such as 'laser tag' were 
reclassified as Level 1 words in the input screen. Proper nouns (e.g. McDonalds, Shaw) were also reclassified as Level 1 words.

Various indices of lexical diversity were generated for each sample. For the purposes of this study, we focus on the total number of words or tokens (TNW) our index or proxy measure of fluency, and the number of different words (NDW). A spelling error rate was calculated by counting each unique error in the handwritten sample, and dividing by the NDW.

The handwritten writing samples were marked for printing quality from a rubric we adapted from Alston $(1983,1985)$ for the purposes of this research, taking into account the major attributes of printing identified in the research literature and noted earlier.

Figure 2 illustrates the printing rubric.

\begin{tabular}{lllll}
\hline Quality of handwriting: & Shape & Size & Spacing & Slant \\
\hline $\begin{array}{l}\text { Labored: difficult to decipher/ read. Clear signs } \\
\text { of poor fine motor control }\end{array}$ & & & & \\
\hline $\begin{array}{l}\text { Legible: readable with effort. Sufficient f/m } \\
\text { control }\end{array}$ & & & \\
\hline Controlled: Uniform, consistent (4S) traits & & & \\
\hline $\begin{array}{l}\text { Fluent/'in flow': Clear sense of } \\
\text { automaticity/'push behind the pencil': }\end{array}$ & & & \\
speed+accuracy+endurance & & & \\
\hline
\end{tabular}

Figure 2. Trait based rubric for evaluating handwriting.

Standard setting samples of writing were selected for reference purposes. They are included in the figures below.

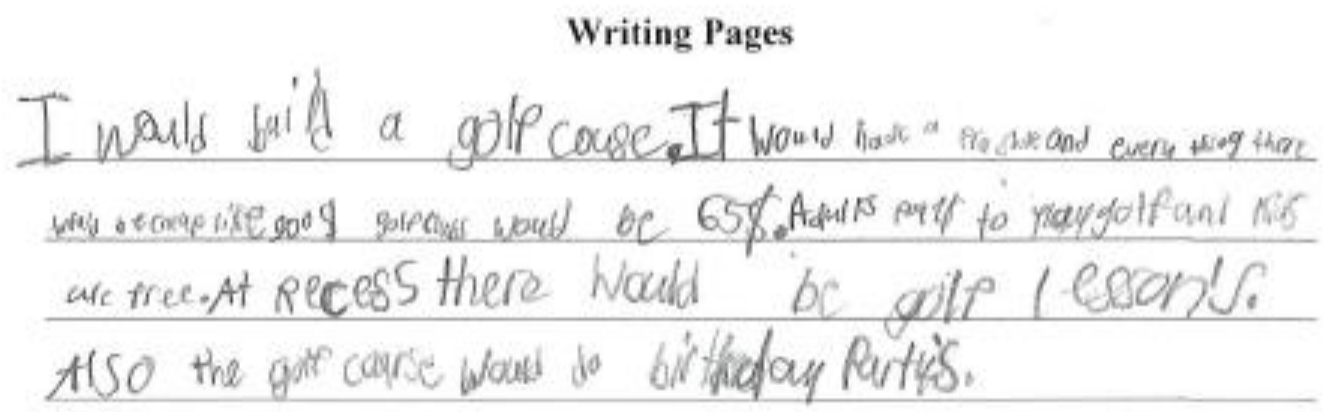

Figure 3. Illustrative sample of Belabored printing.

In the sample above, belabored printing, note the difficulty the writer has in maintaining the line, and the inconsistency in the key features of shape, space, and size that is associated with better quality printing. 
Figure 4 below demonstrates the Legible standard of printing.

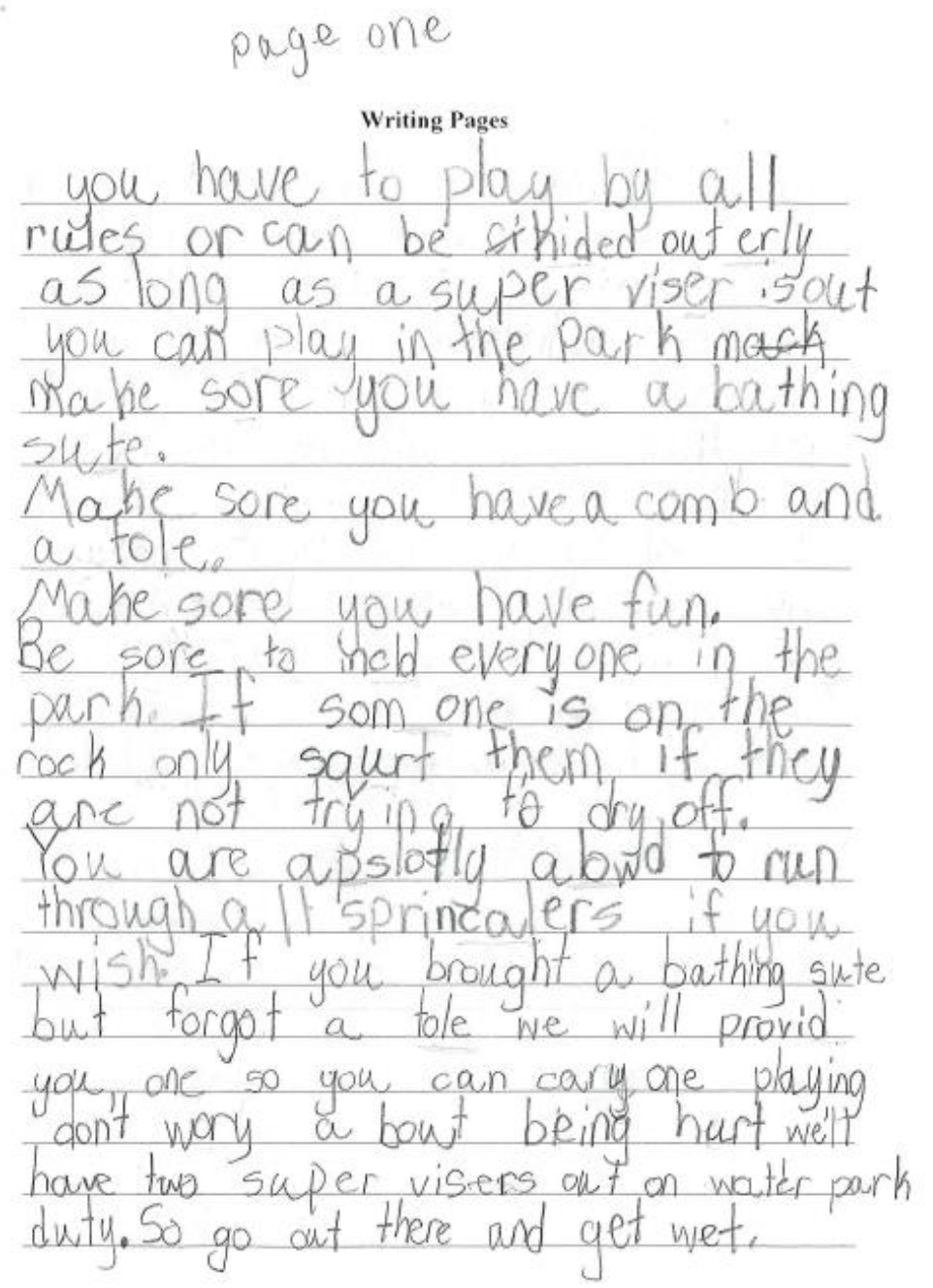

Figure 4. Illustrative sample of Legible printing

The sample above can be read with ease. Shape, size, space and slant, however, are not consistently held under control. This may be leading to the 'one idea at a time', or, 'laundry list' approach to the writing task (i.e. Make sure ...; Make sure ...; Be sure ...). 
Figure 5 below demonstrates the Controlled standard for our Grade 3 data.

If the school was gonna build

something in the wide open

space, I would sugest to build

a sports splex. I'm suggesting

this because then the students

can just do anything in there.

For exsample:play soccer, play hockey, and

basketball. Another reason why

I'm suggesting this becavse

it gives a student a chance to

stay active. Sometimes if some

students were in detention the

teacher could make the students

run laps the whole recess

instead of just sitting there

doing absoulutly nothing. If

the students had gym that day

Figure 5. Illustrative sample of Controlled printing. 
Figure 6 below illustrates a sense of fluency, or 'push behind the pencil'.

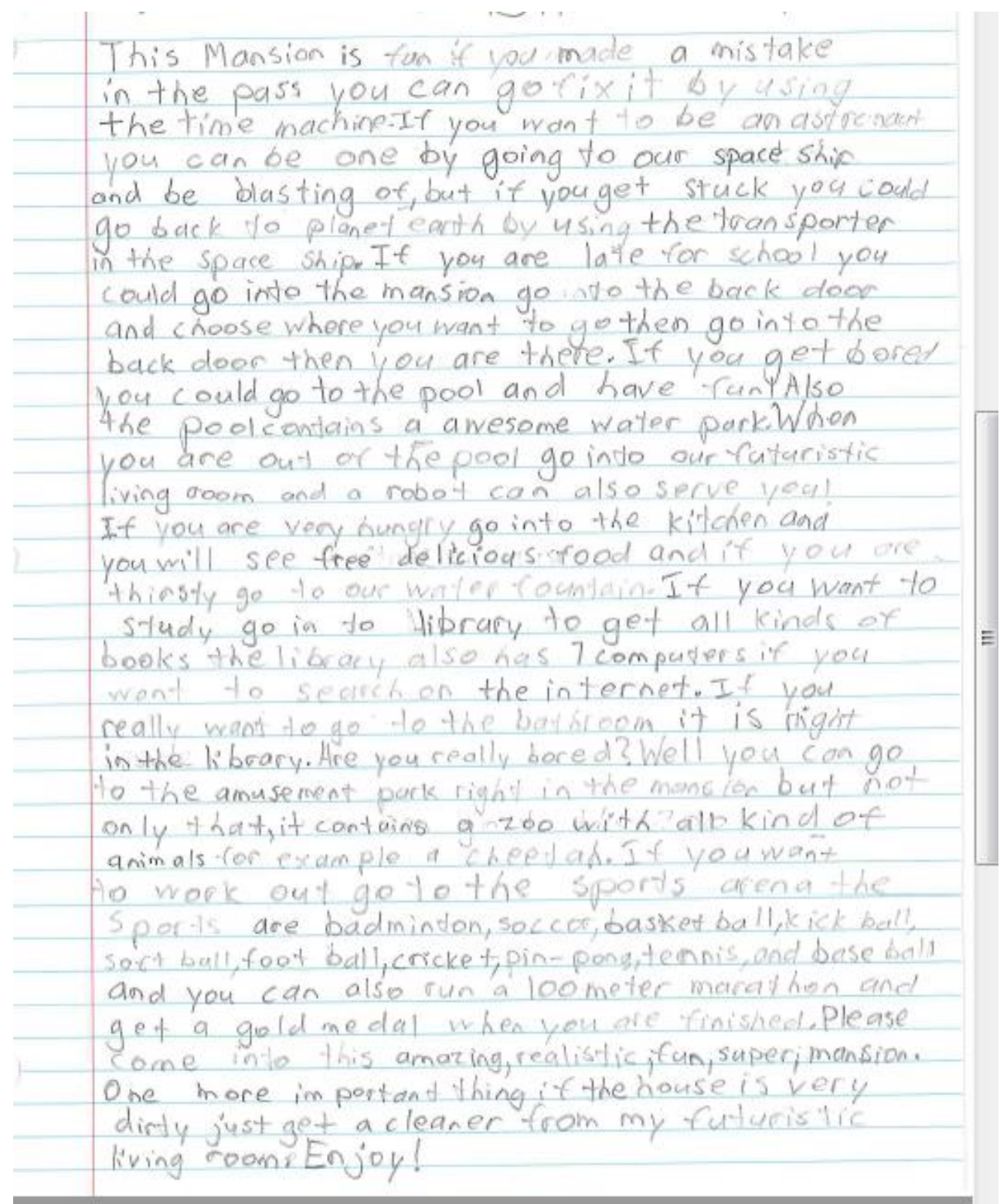

Figure 6. Illustrative sample of Fluent printing at Grade 3.

This young author generated 312 words, and was among those who demonstrated the capacity to move beyond the constraints of handwriting, in turn retrieving or unlocking vocabulary and elaborating ideas. Precise vocabulary choices include blasting, delicious, and contains. A semantic cluster of subject specific words related to the futuristic mansion includes astronaut, time machine, transporter, spaceship, planet, computers, as well as the lexical bundle, search the internet.

Advances in technology enhanced software and computational methods permits convenient and refined insights related to our inquiry questions. Specifically, we sought to 
generate a spelling error rate and an index of writing fluency (total number of words), both made possible on software available in the public domain (www.lextutor.ca/vp/kids).

All quantitative data were initially entered into an Excel spreadsheet; analysis was carried out using SPSS release 19.

\section{Findings}

This section begins with descriptive statistics on the holistic quality ratings of the writing samples, the quality of the handwriting, the fluency of the handwriting as reflected in the TNW generated in the writing samples and the spelling outcomes.

An inferential analysis in response to our first two guiding research questions relating to quality of printing and TNW on the page (i.e. our fluency measure) follows. A mainly non-parametric approach was taken to the inferential analysis.

Table 1 shows the distribution of the quality ratings of the writing samples $(\mathrm{N}=222)$ from 11 Grade 3 classrooms.

\section{Table 1}

Distribution of Holistic Quality Rating Outcomes

\begin{tabular}{clcr}
\hline Holistic Rating & $\begin{array}{l}\text { Proficiency } \\
\text { Standard }\end{array}$ & $\begin{array}{c}\text { Number of } \\
\text { Compositions }\end{array}$ & $\begin{array}{c}\text { Percent of } \\
\text { Sample }\end{array}$ \\
\hline 1 & Limited & 72 & 32.4 \\
\hline 2 & Adequate & 91 & 41.0 \\
\hline 3 & Proficient & 39 & 17.6 \\
\hline 4 & Excellent & 20 & 9.0 \\
\hline Total & & 222 & 100.00 \\
\hline
\end{tabular}

Most of the writing, $73.4 \%$ is rated as either limited or adequate. Few students achieved the standard of excellence. An important goal of our inquiry is to seek explanatory insights related to the influence of handwriting on the quality writing outcomes for these students.

Table 2 shows the distribution of the quality of handwriting by way of four standards: belabored, legible, controlled and fluent (recall Figure 2). 
Table 2

Distribution of Quality of Handwriting/Printing

\begin{tabular}{cccr}
\hline $\begin{array}{c}\text { Quality of } \\
\text { Handwriting }\end{array}$ & $\begin{array}{l}\text { Quality } \\
\text { Standard }\end{array}$ & $\begin{array}{c}\text { Number of } \\
\text { Compositions }\end{array}$ & $\begin{array}{c}\text { Percent of } \\
\text { Sample }\end{array}$ \\
\hline 1 & Belabored & 30 & 13.5 \\
\hline 2 & Legible & 120 & 54.0 \\
\hline 3 & Controlled & 65 & 29.3 \\
\hline 4 & Fluent & 7 & 100.00 \\
\hline
\end{tabular}

These data indicate the vast majority of Grade 3 students $(67.5 \%)$ are printing at either the belabored or legible level; $29.3 \%$ demonstrate control over handwriting. Just a very few students had shifted to a type of connected script, or were experimenting with cursive style. Very few are yet able to achieve fluency or 'flow' in their handwriting, as reflected in a sense of automaticity and push behind the pencil. Even a cursory consideration of data presented in Tables 1 and 2 suggests a connection between the writing outcome standard and the quality of handwriting. We pursue this connection further in our analysis of the data.

Table 3 illustrates the range and the mean total number of words (TNW) for each writing outcomes standard. Recall that TNW was our proxy for writing fluency.

Table 3

Range and Mean TNW for Each Writing Standard 


\begin{tabular}{cccc}
\hline Holistic Rating & $\begin{array}{l}\text { Proficiency } \\
\text { Standard }\end{array}$ & Range in TNW & $\begin{array}{c}\text { Mean } \\
\text { TNW }\end{array}$ \\
\hline 1 & Limited & $11-196$ & 59.08 \\
\hline 2 & Adequate & $52-285$ & 122.81 \\
\hline 3 & Proficient & $91-371$ & 168.72 \\
\hline 4 & Excellent & $132-418$ & 265.75 \\
\hline
\end{tabular}

These data also indicate a connection between fluency of handwriting and the writing outcomes standard. Note the enormous range in TNW -- that is, the least and most total words generated for each of the 4 proficiency standards. Similarly, the mean number of words for each proficiency standard reflects a pronounced gap, especially between those who scored at the limited standard and those at the proficient and excellent standard. The excellent samples far outdistance those at only the limited or adequate standards.

Next we turn to the question of spelling proficiency. Table 4 displays the range and mean number of words spelled correctly for each writing standard.

Table 4

Range and Mean Number of Words Spelled Correctly for Each Quality Writing Standard

\begin{tabular}{cccc}
\hline Holistic Rating & $\begin{array}{c}\text { Proficiency } \\
\text { Standard }\end{array}$ & $\begin{array}{c}\text { Range in Spelling } \\
\%\end{array}$ & $\begin{array}{c}\text { Mean } \\
\text { Spelling \% }\end{array}$ \\
\hline 1 & Limited & $55-100$ & 89.15 \\
\hline 2 & Adequate & $75-100$ & 92.79 \\
\hline 3 & Proficient & $74-100$ & 92.00 \\
\hline 4 & Excellent & $88-99$ & 95.75 \\
\hline
\end{tabular}

Note that spelling varied only minimally across the writing standards. Students at this school were strong spellers, mostly in the transitional or correct stage of spelling (recall Figure 1). Our line of inquiry sought to glean insights into the role of spelling on the rating of the writing outcomes. Our pathway to this question is through considering spelling accuracy on the quality of handwriting and our fluency measure (TNW), the underlying predictors of writing outcomes.

A linear regression model was conducted in SPSS. The variables that were entered into the model were distributed appropriately for this analysis (i.e., skew < +/- 2) 
(Tabachnick \& Fidell, 2013). In this model, fluency (TNW) was entered as the outcome variable with the quality of the handwriting (QLBH) and spelling accuracy (\%) entered as predictors. This resulted in a fitting model, $\mathrm{F}(2,219)=23.22, p<.001, \mathrm{R} 2 \mathrm{adj}$ $=.167$. Coefficents for each predictor are listed in Table 5 below.

Table 5

Quality of Handwriting and Spelling Predicting Fluency (TNW)

\begin{tabular}{cccc}
\hline \multicolumn{4}{c}{ Writing Fluency } \\
\hline $\begin{array}{c}\text { Predictor } \\
\text { Variable }\end{array}$ & $\begin{array}{c}\text { Standardized } \\
\text { Coefficient }\end{array}$ & SE & $p$ \\
\hline $\begin{array}{c}\text { Quality of } \\
\text { Handwriting }\end{array}$ & .41 & 6.84 & $<.001$ \\
\hline $\begin{array}{c}\text { Spelling } \\
\text { Accuracy } \%\end{array}$ & .03 & .65 & .58 \\
\hline
\end{tabular}

Both predictors (printing and spelling) are positive and significantly related to fluency (TNW). The contribution of spelling to writing outcome is an indirect one: it plays a role in fluency, which in turn is the strongest predictor of writing outcome. A review of the spelling errors themselves is revealing. First, though young students have largely consolidated their spelling understandings and acumen by age $8-9$, certain systematic and developmental errors remain (Ehri, 1987). These include homophones (e.g. their, there, they're) and within word patterns such as the need to double a consonant (realy/really; acompany/accompany; runing/running), or 'change the $y$ to $i$, and add -es' (butterflys/butterflies). Secondly, we noted use of words that are clearly within either the oral or reading repertoire of the students, but not quite under written control. This is evident from students' best guess or 'invented' spellings (opchenes/options; trussed/trust). While these invented spellings are counted as spelling errors for the purposes of this study, it is important for classroom practitioners to encourage risk-taking that is evident in the writing samples we analyzed, with most students applying phonics knowledge for spelling these words.

Finally, we turn to our first guiding question, investigating the role of fluency of handwriting as visible in the TNW, as this predicts the quality of the writing outcome. An ordinal regression was conducted in SPSS 24 using the PLUM procedure with a logit link function. In this model, writing fluency (TNW) was entered as a predictor and the quality writing standard was entered as the outcome variable. In this model, fluency (TNW) accounted for $59.5 \%$ of the variability in the quality outcome. Table 6 displays the outcomes. 
Table 6

Fluency $(T N W)$ as a Predictor of Writing Outcome

\begin{tabular}{lccc}
\hline \multicolumn{4}{c}{ Writing Quality } \\
\hline $\begin{array}{l}\text { Predictor } \\
\text { Variable }\end{array}$ & Coefficient & $S E$ & $p$ \\
\hline $\begin{array}{l}\text { Fluency } \\
(\mathrm{TNW})\end{array}$ & .030 & .003 & $<.001$ \\
\hline $\begin{array}{l}\text { Pearson } \chi^{2} \\
\text { Nagelkerke } \\
\text { Pseudo } \mathrm{R}^{2}\end{array}$ & $412.75(\mathrm{df}=431)$ & .728 \\
\end{tabular}

In short, fluency as reflected in the TNW is the strongest 'driver' behind the quality of the writing outcome, accounting for a large proportion of the variability in writing outcomes. Table 3 provides tangible evidence of the effects of this measure: longer writing samples were consistently related with stronger writing outcomes. Underlying fluency is the connection between spelling and quality of handwriting.

\section{Discussion}

Our findings accord well with those reported in the research literature. Consistently, a fluent hand is associated with better writing outcomes (Graham, 2009), and better quality of handwriting, demonstrating control, is associated with a more fluent hand. Fluency as measured by TNW is the single strongest predictor of quality writing outcomes for our 222 writing samples.

It becomes clear that the path to better writing outcomes is to provide further instruction in printing, especially in helping young students develop fluency. Too many of our samples, $67 \%$, reflect a 'hand' that is still belabored or only legible. The goal of realizing a more fluent hand means developing control and building up speed. This can be accomplished through a handwriting style that connects letters that do so naturally. Note, for example the ease of the 'th', 'fi, 'fu' combination. Even our fluent sample (Figure 6) does not yet demonstrate these connections at the end of Grade 3. Grade 4 poses accelerated expectations for both increased quality and quantity in expository mode with the concomitant demands for academic vocabulary use (Roessingh, Nordstokke, \& Colp, 2019 a, b). It would seem a key component to realizing success within these expectations would be improved control and fluency in handwriting.

Graham (2009) advocates for a mixed mostly manuscript (mmm) style that is a clean, uncluttered, italic script that evolves easily from the usual printed script with which children will have begun their written literacy learning. The New Zealand Ministry of Education (1985) has long mandated handwriting instruction and provides a good teaching resource available online that illustrates a cursive handwriting style that transitions from a basic italic manuscript to a connected cursive style. The document emphasizes the 
development of legible, fluent handwriting that is easy to teach and learn, and that students can personalize over time.

Instructed support and plenty of opportunities to engage in purposeful writing in an array of genres constitutes the best practices that many researchers have advocated in the past. Narrative genres, for example, lower the cognitive load; affording young writers the opportunity to work on fluency. Expository modes of writing are more cognitively demanding, but permit insights into young writer's ability to access and mobilize rare and sophisticated word choices needed to inform, persuade or explain. These expectations are visible in the $\mathrm{K}-3$ English Language Arts curriculum documents mandated by provincial ministries across Canada.

Spelling counts, but contributes to writing outcomes in an indirect way through its impact on writing fluency (TNW). Since all of the writing samples reflected strong spelling outcomes, this factor did not contribute in discriminating better writing outcomes from weaker ones. It would seem that English orthography is not as difficult as it may seem. As mentioned earlier, this school district places a strong emphasis on printing and spelling in the $\mathrm{K}-2$ years especially, and it would seem that instructed support in spelling has had the intended goal of strong spelling outcomes for all students. Spelling errors observed are systematic, and following Ehri's model (1987), developmental in nature. This suggests that ongoing instruction in spelling will be beneficial in correcting these errors. Further, as word use shifts to academic vocabulary, a focus on the morphology and spellings of Greek and Latin roots is needed.

The 'look' of the printing was the single biggest contributor to the quality writing standard of the 222 writing samples collected for the study. More than a matter of neatness, it is a matter of demonstrating control over the neuro-motor demands of transcription. Not enough students are reaching this level of handwriting. Our findings corroborate those reported by Kim, Al Otaiba, and Wanzek (2015) and Son and Meisels (2006): youngsters with stronger fine motor control demonstrate stronger literacy achievement. This in turn unlocks linguistic resources, permitting retrieval of rare and sophisticated words that afford precision and nuance in conveying meaning. This is evident in the illustrative sample for 'fluent' handwriting (Figure 6).

A mentioned earlier, this school jurisdiction uses the Writing Road to Reading program consistently in the $\mathrm{K}-2$ years (Spalding, 2012). Other local studies (Roberts et al., 2014; Roessingh \& Bence, 2017) report very good outcomes through the adoption of Handwriting Without Tears (Olsen, 2003) for the printing program. Words Their Way (Bear, Invernizzi, Templeton, \& Johnson, 2014) was favored by the instructional team in Roessingh and Bence's (2017) study with gifted learners in Grade 2. These programs extend beyond Grade 2, and our findings suggest that ongoing instruction in handwriting through Grade 3 and beyond would yield better writing outcomes. This aligns with Graham's (2009) suggestion to dedicate instructional attention on handwriting beyond Grade 2.

Various commercially prepared, or free online resources are available for teachers to adopt.Look for a program that provides explicit, direct instruction; and is developmentally progressive and engaging. Consistent scheduling, and a concerted grade team approach from $\mathrm{K}-3$ makes it easier for young learners to recognize familiar routines and approaches to the printing and spelling program. 
Overall, our findings accord well with others reported in the research literature cited in the literature review. Like others, our findings suggest room for improvement, and the importance of intervention in the Grade 3 year to keep our young learners on track. Findings from the neurosciences in particular illuminate the complexity and interrelatedness of the neuro-motor, linguistic and cognitive domains in realizing literacy development among young learners. However, like any endeavor that includes technical elements - such as playing the piano, ice dancing, or piloting a jumbo jet, underlying skills require disciplined, effortful, mindful rehearsal and practice, and a good teacher - someone who provides explicit instruction and feedback.

We make an important contribution in translating our findings into usable benchmarks for handwriting and fluency (TNW): together, these predict writing outcomes. The rubrics we have adapted for the purposes of our work, and the illustrative samples of students' writing provide guidance to classroom practitioners. The prompt and the protocol for its administration provide simple assessment ideas for teachers, and our fluency guidelines reflected in the TNW for each quality writing outcome will be very useful for teachers. The use of the online vocabulary profiling software is an additional tool that is accessible and easy to use. We encourage Grade 3 teachers to work in a more systematic, collaborative fashion in small communities of practice (COPS), using the tools and findings we present to transform their literacy instruction, and in turn, to improve writing outcomes.

\section{Limitations of our Study}

As noted above, our study is confined to one small school jurisdiction of 2,800 students, chosen strategically for its strong focus on foundational learnings and basic skills instruction in the $\mathrm{K}-2$ years. A previous study of a Grade 2 cohort from this school jurisdiction (Roessingh, 2013) reflected this strong focus in the early literacy program: 93\% of the students achieved at the satisfactory standard or better for the overall quality of their writing. Nevertheless, this presents its own limitations. Because this school is a school of parental choice, there is a self-selection element at play, reflected in the overall demographic profile of the school. While students are overall considered to be typical young learners, we are cognizant of factors related to school culture (uniforms; a consistent, school-wide designed instruction that focuses on foundational learnings and basic skills development; and consistent expectations and assignment of homework) and parental expectations that play a role in children's early literacy development.

It should be noted that adoption of the trait-based rubric for evaluating the quality standard for each sample represents simply one perspective of writing. However, a perusal of the research on the development of writing reflects a high degree of consensus concerning the features or traits of good quality writing including interesting ideas and topic development, organization, word choice, and conventions. The administration protocol and setting an expository prompt for obtaining the writing samples is another choice we made, cognizant of the trade-offs this would entail. Time, topic familiarity and genre, for example, all constrain writers' abilities to put words on the page. In the interests of obtaining the samples in the classroom context and encouraging the young writers to submit their best efforts on an authentic-like writing task, we sought to minimize stress around a 'test' setting (most students did not realize this was 'a test'); to adopt a process approach to the writing (the pre-writing drawing and outlining, the writing and reflection statements) within one period of time to sit the writing task; and to provide sufficient time 
for students to develop their ideas on a topic that was familiar yet challenging for them. As mentioned earlier, ecological validity in data collection and analysis was an important consideration for its potential to interpret and translate clinical studies that predominate the written literacy research into usable frameworks and benchmarks for practitioners.

\section{Conclusion}

'Off to a good start' is not enough to assume that children's ongoing written literacy learning will develop and progress without sustained, direct handwriting instruction. This finding is underscored consistently by others in the research community (Graham, 2009; Moats, n.d.). Our findings corroborate those reported by others. There is something to be said about handwriting that demonstrates control of execution that suggests more than a matter of neatness. Far more important is its connection to fluency and in turn, the ability to unlock the higher order and more complex skills associated with text generation, in Berninger's (1999) simple view of writing model.

No one advocates for a return to the skill/drill/kill approaches to spelling instruction of years past. Rote and mindless repetition disappeared from the curriculum decades ago. Decontextualized word lists for the weekly spelling test, and look up and copy from the dictionary tasks are similarly devoid of meaning (Schlagal, 2001). At the conceptual heart of becoming literate lies the ability to make and convey meaning. Young writers need the tools, skills and strategies to achieve this: few children in Canada lack the ability to do so.

We encourage others in the scholarly community to conduct classroom research that has the possibility of gleaning research insights that are relevant to the classroom context and the daily exigencies of literacy teaching and learning in the $\mathrm{K}-3$ years and beyond. We would welcome replication studies or our work, or extensions of our work in various public education settings. Missing from the tool kit of many elementary practitioners are the rubrics, exemplars and benchmarks that can guide their instructional decision making and assessment practices. In this article we have stayed focused on our goal of effecting change in the classroom and beyond. It is common for Ministries of Education to assess early literacy achievement some time in Grade 3 or 4 . We hope our work contributes to a broader conceptualization and understanding of early literacy learning and its assessment.

\section{Acknowledgements}

This research was supported through an AACES grant (ATA). We acknowledge with gratitude our partnering research school, Foundations for the Future. We are grateful for the feedback received from those reviewers who provided specific, encouraging directions to improve our work, and we extend our appreciation to the editorial team at Language and Literacy who shepherded our manuscript through the publication process. Thank you.

\section{References}

Alston, J. (1983). A legibility index: Can handwriting be measured? Educational Review, 35(3), 237-242. Retrieved from http://dx.doi.org/10.1080/0013191830350305 
Alston, J. (1985). The handwriting of seven to nine year olds. British Journal of Special Education, 12(2), 68-72. Retrieved from http://onlinelibrary.wiley.com/doi/10.1111/j.1467-8578.1985.tb00609.x/abstract

American Association for School Administrators. (2012). Handwriting in the $21^{\text {st }}$ century: An educational summit. Retrieved from https://www.hw21summit.com/

Anderson, D. (1969). What makes handwriting legible? Elementary School Journal, 69(7), 364-369. Retrieved from http://www.jstor.org.ezproxy.lib.ucalgary.ca/stable/pdf/1000270.pdf

Applebee, A., \& Langer, J. (2006). The state of writing instruction in America's schools: What existing data tell us. Center on English Learning \& Achievement, University at Albany State University of New York. Retrieved from http://citeseerx.ist.psu.edu/viewdoc/download?doi=10.1.1.541.4136\&rep=rep1\&t ype $=$ pdf

Applebee, A., \& Langer, J. (2009). What is happening in the teaching of writing? English Journal, 98(5), 18-28. Retrieved from https://eric.ed.gov/?id=EJ842316

Bear, D., Invernizzi, M., Templeton, S., \& Johnson, F. (2014). Words their way (5th ed.). Essex: Harlow.

Berninger, V. (1999). Coordinating transcription and text generation in working memory during composing: Automatic and constructive processes. Learning Disability Quarterly, 22, 99-112. Retrieved from http://journals.sagepub.com/doi/pdf/10.2307/1511269

Berninger, V., Vaughan, K., Abbott, R., Begay, K., Coleman, K., Curtin, G., Hawkins, J., \& Graham, S. (2002). Teaching spelling and composition alone and together: Implications for the simple view of writing. Journal of Educational Psychology, 94(2), 291-304. Retrieved from http://dx.doi.org/10.1037/0022-0663.94.2.291

Boekaerts, M., Nieuwenhuizen, C., \& Seegers, G. (1992). Quality of handwriting: Selfassessment as a tool for improvement. Conference Proceedings: European Conference for Educational Research, 314-316. ED350334. Retrieved from http://doc.utwente.nl/96172/1/ED350334.pdf

Bourne, L. (2007). Cursive vs printing: Is one better than the other? [blog entry]. Retrieved from http://www.blog.montessoriforeveryone.com/cursive-vs-printingis-one-better-than-the-other.html

Christensen, C. (2005). The role of orthographic-motor integration in the production of creative and well-structured written text for students in secondary school.

Educational Psychology, 25(5), 441-453. Retrieved from https://doi.org/10.1080/01443410500042076

Christensen, C. (2009). The critical role handwriting plays in the ability to produce high quality written text. In R. Beard, D. Myhill, J. Riley \& M. Nystrand (Eds.), The Sage handbook of writing development (pp. 284-299). Sage Publications. Retrieved from http://dx.doi.org/10.4135/9780857021069.n20

Connelly, V., \& Hurst, G. (2001). The influence of handwriting fluency on writing quality in later primary and early secondary education. Handwriting Today, 2, 557.

Coxhead, A. (2000). A new academic word list. TESOL Quarterly, 34(2), 213-238. Retrieved from https://onlinelibrary.wiley.com/doi/abs/10.2307/3587951 
Cutler, L., \& Graham, S. (2008). Primary grade writing instruction: A national survey. Journal of Educational Psychology, 100(4), 907- 919. Retrieved from https://www.semanticscholar.org/paper/Primary-grade-writing-instruction\%3AA-national-Cutler-Graham/12a3e9d4bdf3bba9efd64ce7de2a178ef3ffdaad

Dinehart, L. (2014). Handwriting in early childhood education: Current research and future implications. Journal of Early Childhood Literacy, 15(1), 97-118.

Retrieved from http://journals.sagepub.com/doi/abs/10.1177/1468798414522825

Ehri, L. (1987). Learning to read and spell words. Journal of Reading Behavior, 19(1), 531. Retrieved from https://journals.sagepub.com/doi/pdf/10.1080/10862968709547585

Gentry, R. (1982). An analysis of development in spelling in GNYS AT WORK. The Reading Teacher, 36(2), 192-200. Retrieved from https://www.jstor.org/stable/pdf/20198182.pdf

Gentry, R. (2002). The literacy map: Guiding children to where they need to be. NY: Mondo Publishing.

Gentry, R. (2010). How well do you spell? Find out in 60 seconds. Psychology Today, October 28, 2010. Retrieved from https://www.psychologytoday.com/ca/blog/raising-readers-writers-andspellers/201010/how-well-do-you-spell-find-out-in-sixty-seconds

Graham, S., Berninger, V., \& Weintraub, N. (1998). The relationship between handwriting style and speed and legibility. The Journal of Educational Research, 91(5), 290-297. Retrieved from http://dx.doi.org/10.1080/00220679809597556

Graham, S., Berninger, V., \& Weintraub, N. (2001). Which manuscript letters to primary grade children write legibly? Journal of Educational Psychology, 93(3), 488- 497.

Graham, S. (2009). Want to improve children's writing? Don't neglect their handwriting. American Educator, 33(4), 20-40. Retrieved from https://www.aft.org/pdfs/americaneducator/winter2009/graham.pdf

Johnson, R. L., Penny, J., Fisher, S., \& Kuhs, T. (2003). Score resolution: An investigation of the reliability and validity of resolved scores. Applied Measurement in Education, 16(4), 299-322.

Jones, D., \& Christensen, C.A. (1999). Relationship between automaticity in handwriting and students' ability to generate written text. Journal of Educational Psychology, 91(1), 44-49.

Joshi, M., Treiman, R., Carreker, S., \& Moats, L. (2008). How words cast their spell: Spelling is an integral part of learning the language, not a matter of memorization. American Educator, Winter 2008-2009. 6-8. Retrieved from http://www.aft.org/pdfs/americaneducator/winter0809/joshi.pdf

Kim, Y., Al Otaiba, S., \& Wanzek, J. (2015). Kindergarten predictors of third grade writing. Learner Individual Differences, 37, 27- 37. Retrieved from https://www.ncbi.nlm.nih.gov/pmc/articles/PMC4308812/

Korbey, H. (2013). Should schools still teach cursive? MindShift: How we will learn. [blog entry]. Retrieved from http://blogs.kqed.org/mindshift/2013/06/shouldschools-still-teach-cursive/

Moats, L. (n.d.). How children learn to spell. Retrieved from https://www.scholastic.com/teachers/articles/teaching-content/how-childrenlearn-spell/ 
McCutchen, D. (1996). A capacity theory of writing: Working memory in composition. Educational Psychology Review, 8(3), 299-325. Retrieved from https://link.springer.com/article/10.1007/BF01464076

Medwell, J., Strand, S., \& Wray, D. (2007). The role of handwriting in composing for Y2 children. Journal of Reading, Writing and Literacy, 2(1), 11-21. Retrieved from https://www.academia.edu/2629891/The role_of handwriting_in_composing for Y2 children?auto=download

Medwell, J., \& Wray, D. (2008) Handwriting - a forgotten language skill? Language and Education, 22 (1), 34-47. Retrieved from http://dx.doi.org/10.2167/le722.0

Medwell, J., \& Wray, D. (2014). Handwriting automaticity: The search for performance thresholds, Language and Education, 28(1), 34-51. Retrieved from http://dx.doi.org/10.1080/09500782.2013.763819

Morin, M., LaVoie, N., \& Montesinos, I. (2012). The effects of manuscript, cursive or manuscript/cursive styles on writing development in Grade 2. Language and Literacy, 14(1), 110- 124. Retrieved from https://journals.library.ualberta.ca/langandlit/index.php/langandlit/article/view/11 $\underline{028 / 13067}$

Nagy, W., Berninger, V., Abbott, R., Vaughan, K., \& Vermeulen, K. (2003). Relationship of morphology and other language skills to literacy skills in at-risk second-grade readers and at-risk fourth-grade writers. Journal of Educational Psychology, 95, 730-742.

National Handwriting Association. Why handwriting is important. Retrieved from http://www.nha-handwriting.org.uk/handwriting/why-is-handwriting-important

Nelson, N., \& Van Meter, A. (2007). Measuring written language ability in narrative samples. Reading \& Writing Quarterly, 23(3) 287-309. Retrieved from http://www.tandfonline.com/doi/pdf/10.1080/10573560701277807?needAccess=t $\underline{\text { rue }}$

New Zealand Ministry of Education (1985). Teaching Handwriting. Retrieved from http://www.uobabylon.edu.iq/eprints/publication_12_8303_47.pdf

Olsen, J. (2003). Handwriting without tears. Cabin John, MD: Western Psychological Services.

Peverly, S. (2006). The importance of handwriting speed in adult writing. Developmental Neuropsychology, 29(1), 197-216. Retrieved from http://dx.doi.org/10.1207/s15326942dn2901_10

Pontart, V., Bidet-Ildei, C., Lambert, E., Morisset, P., Flouret, L., \& Alamargot, D. (2013). Influence of handwriting skills during spelling in primary and lower secondary grades. Frontiers in Psychology, 4, 818. Retrieved from http://www.ncbi.nlm.nih.gov/pmc/articles/PMC3817363/

Prensky, M. (2005). Shaping tech for the classroom. Edutopia, Dec. 2, 2005. Retrieved from http://www.edutopia.org/adopt-and-adapt-shaping-tech-for-classroom

Reed, D. (2012). Why teach spelling? Centre on Instruction at RMC Research Corp. Retrieved from https://keystoliteracy.com/wp-content/pdfs/orcgenlit/Why\%20Teach\%20Spelling.pdf

Roberts, G., Derkach-Ferguson, A., Siever, J., \& Rose, M. (2014). An examination of the effectiveness of Handwriting Without Tears® instruction. Journal of 
Occupational Therapy, 81(2), 102-113. Retrieved from

http://journals.sagepub.com/doi/abs/10.1177/0008417414527065

Roessingh, H. (2013). A look at Grade 2 writing: Successes and challenges in early literacy development. Learning Landscapes, 7(1), 269-281. Retrieved from http://learninglandscapes.ca/index.php/learnland/article/view/642/642

Roessingh, H., \& Elgie, S. (2015). From thought, to words, to print: Early literacy development in Grade 2. Alberta Journal of Educational Research, 60(3), 576597. Retrieved from http://esl-almadina.com/wp-content/uploads/2016/12/FromThought-to-Words-to-Print-Early-Literacy-Development-in-Grade-2.pdf

Roessingh, H., Douglas, S., \& Wojtalewicz, B. (2016). Lexical standards for expository writing at Grade 3: The transition from early literacy to academic literacy. Language and Literacy, 18(3), 123-144. Retrieved from https://journals.library.ualberta.ca/langandlit/index.php/langandlit/article/view/24 $\underline{645 / 21011}$

Roessingh, H., \& Bence, M. (2017). Intervening in early written literacy development for gifted children in Grade 2: Insights from an action research project. Journal for the Education of the Gifted, 40(2), 168-196. Retrieved from https://doi.org/10.1177/0162353217701201

Roessingh, H., Nordstokke, D., \& Colp. M. (2019a). Unlocking academic literacy in Grade 4: The role of handwriting. Reading and Writing Quarterly: Overcoming learning difficulties, 35(2), 65-83. Retrieved from https://doi.org/10.1080/10573569.2018.1499160

Roessingh, H., Nordstokke, D., \& Colp, M. (2019b). Beyond presentation effects: Understanding the role of language by hand in the holistic quality rating of young students' writing in Grade 4. Alberta Journal of Educational Research, 65(1), 72 93. Retrieved from https://journalhosting.ucalgary.ca/index.php/ajer/article/view/56630/pdf

Rosenblum, S., Weiss, P., \& Parush, S. (2003). Product and process evaluation of handwriting difficulties: A review. Educational Psychology Review, 15(1), 41-81. Retrieved from https://www.researchgate.net/publication/227117736_Product_and_Process_Eval uation_of_Handwriting Difficulties

Saperstein Associates (2012). Handwriting in the $21^{\text {st }}$ century: Research shows why handwriting belongs in today's classroom. Retrieved from https://www.hw21summit.com/media/zb/hw21/files/H2948_HW_Summit_White Paper_eVersion.pdf

Schlagal, B. (2001). Traditional, developmental, and structured approaches to spelling. Annals of Dyslexia, 51(1), 147-176. Retrieved from https://www.jstor.org/stable/23765367?seq=1\#page_scan_tab_contents

Son, S., \& Meisels, S. (2006). The relationship of young children's motor skills to later reading and math achievement. Merrill-Palmer Quarterly, 52(4), 755-778. Retrieved from http://dx.doi.org/10.1353/mpq.2006.0033

Spalding, R. (2012). The writing road to reading (6th ed.). NY: Harper Collins.

Spear-Swering, L. (2006). The importance of teaching handwriting. LDonline. Retrieved from 
http://www.ldonline.org/spearswerling/The_Importance_of_Teaching_Handwritin $\mathrm{g}$

Stevenson, N., \& Just, C. (2014). In early education, why teach handwriting before keyboarding? Early Childhood Education Journal, 42(1), 49-56. Retrieved from https://www.researchgate.net/publication/257556613_In_Early_Education_Why Teach_Handwriting_Before_Keyboarding

Tabachnick, B.G., \& Fidell, L. (2013). Using multivariate statistics $\left(6^{\text {th }}\right.$ ed.). Toronto: Pearson.

Treiman, R., \& Bourassa, D. (2000). The development of spelling skills. Topics in Language Disorders, 20(3), 1-18. Retrieved from http://pages.wustl.edu/files/pages/imce/treiman/treiman_bourassa_2000the development_of_spelling_skill-published.pdf

Vangelova, L. (2015, February 9). How spelling keeps kids from learning. The Atlantic. Retrieved from https://www.theatlantic.com/education/archive/2015/02/how-theenglish-language-is-holding-kids-back/385291/

\section{Author Biography}

Dr. Hetty Roessingh is a long time ESL practitioner, focusing her research on early language and literacy development. Recent work has extended to include the impact of fine motor control, handwriting and spelling on the quality outcomes of all young students. This unlocks the vocabulary knowledge 'on the page' which in turn allows us to provide the targeted instruction that many young English language learners need.

Dr. David Nordstokke has a research focus on high school transitions to post-secondary, and resiliency among students. His current work on early language and literacy development and the role of handwriting is also a new direction in research endeavor. 


\section{WRITING TASK}

All students in the school are asked to do some writing. Read the information below and think about how you will do the writing assignment.

\section{TO THINK ABOUT BEFORE WRITING}

Imagine that there is a large undeveloped space in your schoolyard. Every student in the school has been asked for ideas about what to put there. A committee of teachers and parents will choose the best suggestion.

\section{IN YOR WRITING}

Write a proposal for the committee to read. Describe what you would put in the space. Then, convince the committee that your idea is the best way to use the space.

\section{DIRECTIONS FOR WRITING}

You will have up to 60 minutes to plan and write, so budget your time carefully. Use the PLANNING page to plan your writing. You may brainstorm, web, draw, or list ideas. Think of details that will be interesting and entertaining.

Use the WRITING pages to write a first draft. You may show changes and corrections on your first draft. Do not write a 'good copy'. If you need more space to write, use the back of the writing pages. Please number your extra pages.

Your work will be evaluated on WHAT your write and HOW WELL you write. Remember to:

- CONSIDER your audience

- $\quad$ PRESENT your ideas in prose

- $\quad$ ORGANIZE your writing as required by the task

- $\quad$ FOCUS on the purpose of your writing 
Appendix B: Trait based writing rubric adopted for our research

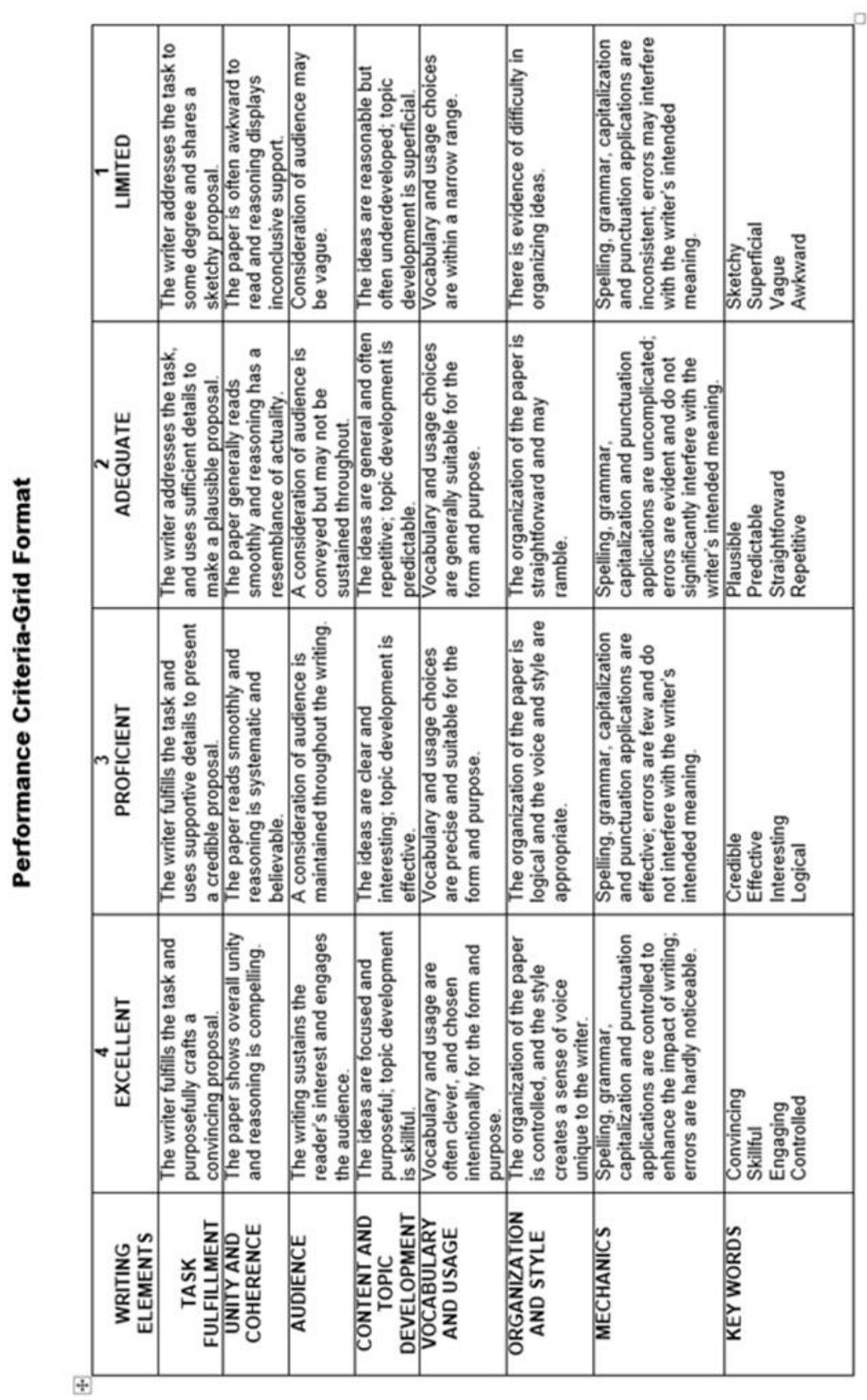

